US Army Corps of Engineers

Waterways Experiment Station
US-CE-C Property of the

United States Government

\title{
U.S. Army Engineer Waterways Experiment Station Major Shared Resource Center Benchmark Results and Analysis; Performance Level 1
}

by John E. West, Alex R. Carrillo

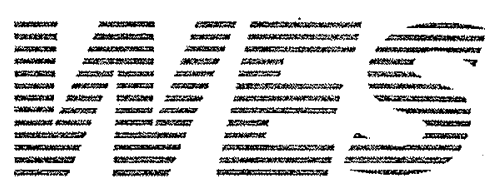

Approved For Public Release; Distribution Is Unlimited

Research Library

US Army Engineer Waterways

Experiment Station

Vicksburg. Alississippi 
The contents of this report are not to be used for advertising, publication, or promotional purposes. Citation of trade names does not constitute an official endorsement or approval of the use of such commercial products.

The findings of this report are not to be construed as an official Department of the Army position, unless so designated by other authorized documents.

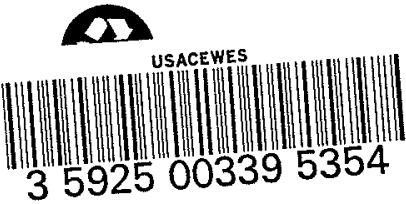




\section{U.S. Army Engineer Waterways Experiment Station Major Shared Resource Center Benchmark Results and Analysis; Performance Level 1}

by John E. West, Alex R. Carrillo U.S. Army Corps of Engineers Waterways Experiment Station 3909 Halls Ferry Road

Vicksburg, MS 39180-6199

Preliminary report

Approved for public release; distribution is unlimited 


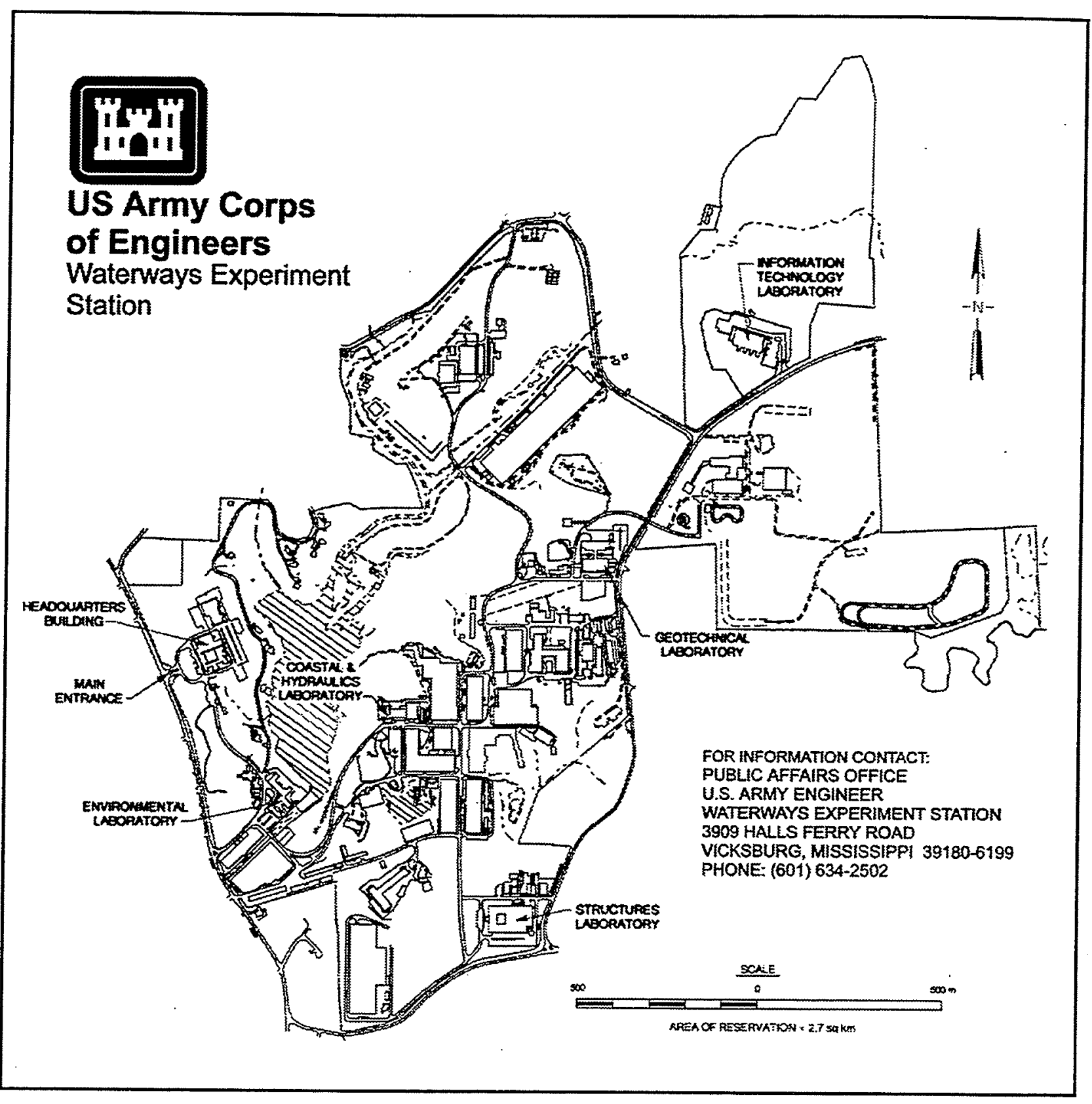

Waterways Experiment Station Cataloging-in-Publication Data

West, John E.

U.S. Army Engineer Waterways Experiment Station major shared resource center benchmark results and analysis : performance level 1 / by John E. West, Alex R Carrillo; prepared for U.S. Army Corps of Engineers.

41 p. : ill. ; $28 \mathrm{~cm}$. -- (Technical report; ITL-97-3)

Includes bibliographic references.

1. High performance computing -- United States -- Army. 2. Benchmarking (Management) - United States -- Army. 3. System analysis -- United States -- Army. 4. Operations research -- United States - Army. I. Carrillo, Alejandro R. II. United States. Army. Corps of Engineers. III. U.S. Army Engineer Waterways Experiment Station. IV. Information Technology Laboratory (U.S. Army Engineer Waterways Experiment Station) V. Title. VI. Series: Technical report (U.S. Army Engineer Waterways Experiment Station) ; ITL-97-3.

TA7 W34 no.ITL-97-3 


\section{Contents}

Preface $\quad$ iv

Executive Summary $\quad$ v

1 Background 1

1.1 The Nichols Research Corporation Proposal . . . . . . . . . . . . . . . 1

2 SGI Power Challenge Array $\quad 3$

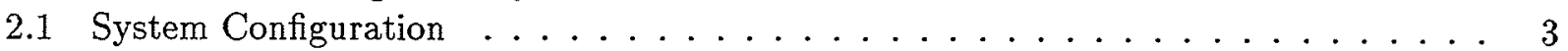

2.2 Witnessed Benchmark . . . . . . . . . . . . . . . . 3

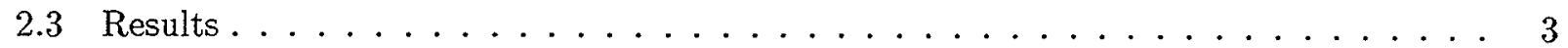

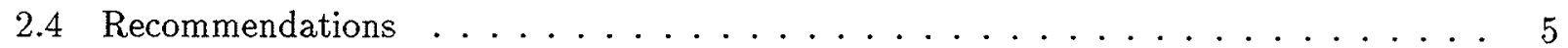

3 CRAY T3E $\quad 9$

3.1 System Configuration $\ldots \ldots \ldots \ldots \ldots \ldots \ldots$

3.2 Witnessed Benchmark . . . . . . . . . . . . . . . 10

3.3 Results . . . . . . . . . . . . . . . . . . . . . . 10

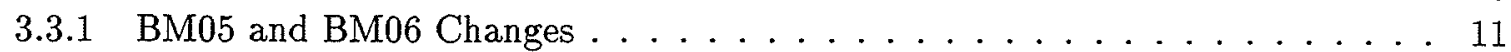

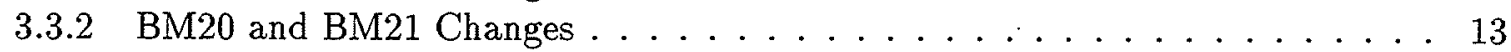

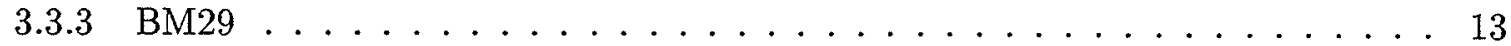

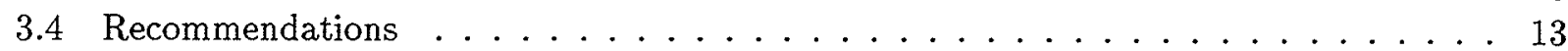

4 Summary and Recommendations 14

A Supporting Data: Power Challenge Array $\quad$ A1

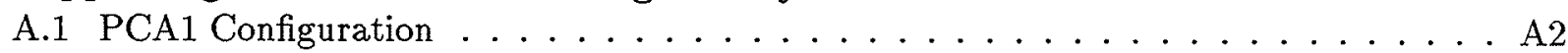

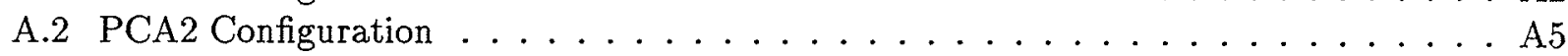

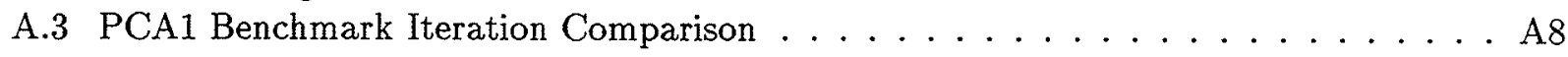

A.4 PCA2 Benchmark Iteration Comparison . . . . . . . . . . . . . . A11

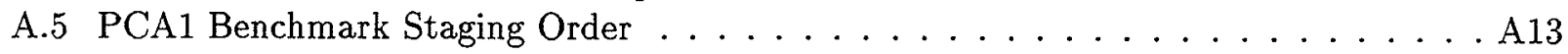

A.6 PCA2 Benchmark Staging Order . . . . . . . . . . . . . A A14

B Supporting Data: CRAY T3E $\quad$ B1

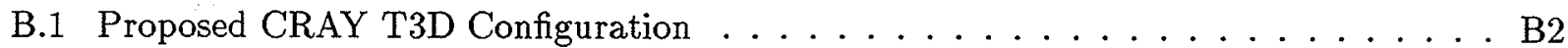

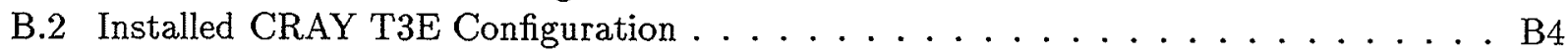




\section{List of Figures}

2.1 PCA1 proposed and witnessed benchmark staging and duration. . . . . . . . 6

2.2 PCA2 proposed and witnessed benchmark staging and duration. . . . . . . . . 7

3.1 CRAY T3D (proposed) and CRAY T3E (witnessed) benchmark staging and duration. 12 


\section{List of Tables}

1.1 NRC proposal benchmark times. . . . . . . . . . . . . . . 2

2.1 Benchmark iterations for each chassis. . . . . . . . . . . . . . 4

2.2 Power Challenge Array witnessed benchmark times. . . . . . . . . . . . . 4

3.1 Benchmark iterations for the CRAY T3E and measured time. . . . . . . . 10 


\section{Preface}

This report ${ }^{1}$ presents results and analysis of the Performance Level 1 target configuration benchmark for the DoD High Performance Computing (HPC) Major Shared Resource Center (MSRC) at the U.S. Army Engineer Waterways Experiment Station (WES). The MSRC at WES is operated as part of the DoD HPC Modernization Program of the Director, Defense Research and Engineering. Performance Level 1 refers to the first major phase of enhancements being made to the capabilities and capacities of the MSRC by Nichols Research Corporation, the integration contractor for the MSRC.

This work was performed by John E. West and Alex R. Carrillo, DoD High Performance Computing Center, Information Technology Laboratory (ITL), WES, Vicksburg, MS. The work was under the direction of Dr. N. Radhakrishnan, Director, ITL.

During preparation of this report, Dr. Robert W. Whalin was Director of WES. COL Bruce K. Howard, EN, was Commander.

\footnotetext{
${ }^{1}$ The contents of this report are not to be used for advertising, publication, or promotional purposes. Citation of trade names does not constitute an official endorsement or approval of the use of such commercial products.
} 


\section{Preliminary Investigation Executive Summary}

Upon installation of the Performance Level 1 target configuration, the government's integration contract requires that the contractor demonstrate that the performance levels achieved by the installed configuration match those cited in the offeror's proposal for the Major Shared Resource Center (MSRC) target configuration High Performance Computing (HPC) resources. This demonstration, referred to herein as the "witnessed benchmark," has been completed, and preliminary results indicate several areas of concern.

The proposed configuration consisted of an SGI Power Challenge Array, a CRAY T3D, and a CRAY C90. The installed configuration consists of an SGI Power Challenge Array, a CRAY T3E, and a CRAY C90. The impact of the substitution of the CRAY T3E on code changes has been assessed and found to be minimal. Furthermore, the Measured Benchmark Time of the installed configuration, 6317 seconds, is less than the time for the proposed configuration, 6338 seconds.

However, analysis of the supplied benchmark data indicates that several concerns must be addressed before the benchmark can be recommended as successfully completed:

\section{Power Challenge Array}

- The I/O benchmark for the SGI Power Challenge Array must be rerun to demonstrate that the system can achieve the $100 \mathrm{MByte} / \mathrm{sec}$ transfer rate required in Section C.5.1.1.2.4 of the RFP.

- The government must have the opportunity to witness the execution of a single iteration of BM27 to resolve questions over the origin of the executable for this benchmark.

- A written explanation for the longer than proposed run time of the witnessed Power Challenge Array benchmark must be provided for further assessment.

\section{CRAY T3E}

- Although the changes made to the benchmarks for the CRAY T3E are few and are not found to introduce significant new complexity, they seem primarily directed to performance enhancements and not porting issues. The contractor must provide an explanation and justification for these changes.

- Evidence of I/O benchmark execution on the CRAY T3E was not found; such evidence is required and must be supplied by the contractor before final acceptance of this system.

- There is a discrepancy between the session log file which recorded the full details of the entire witnessed benchmark process and the supporting data and individual logs for BM29. The session log indicates a failed compilation due to a streams variable, while the individual log for BM29 does not indicate a problem. The contractor must provide an explanation of this discrepancy.

- The government must have the opportunity to witness the execution of a single iteration of BM29 to resolve questions over the origin of the executable for this benchmark. 



\section{Chapter 1}

\section{Background}

The benchmarking process for the Department of Defense (DoD) Major Shared Resource Center (MSRC) procurement was designed to measure the ability of the offeror's proposed technical solution to satisfy the government's computational workload. For purposes of this contract, the workload is represented by a suite of codes assembled by the government from candidate applications submitted in each of the DoD Computational Technology Areas (CTAs). Offerors proposing a solution for a particular MSRC were then required to submit benchmark results for the set of codes representing the CTAs for which that MSRC was responsible. It was the offeror's responsibility to select a range of High Performance Computing (HPC) architectures and stage the benchmark applications on those machines to demonstrate that the technical configuration provided "best value" to the government. No guidance was given to the offeror concerning application staging or the types of architectures desired in the final solution - any solution which met the specific requirements for service in the Request for Proposal (RFP) was acceptable. To ensure that the government purchased a definable level of hardware performance, each offeror was required to abide by the processing and code change rules set forth in Attachment VI of the RFP. These rules contain limitations on the types of code changes which are allowable and define the information which must be provided to support the reported performance. The most important information which was to be provided in this regard was a listing of the codes changes with explanation and justification. The performance of the proposed target configuration is represented by the Measured Benchmark Time (MBT), computed as the longest of the elapsed (wall clock) times required for each individual measured HPC system to complete the benchmark iterations assigned to it. The magnitude of the MBT was assessed (by the Source Selection Evaluation Board) relative to the number and complexity of the code changes necessary to produce it, with special emphasis on performance "achievability" by "typical" DoD researchers. This qualitative assessment was then used to rate the offeror's technical solution.

\subsection{The Nichols Research Corporation Proposal}

After completion of the Source Selection Evaluation, Nichols Research Corporation (NRC) was awarded the contract for the MSRC at the U.S. Army Corps of Engineers Waterways Experiment Station (WES) MSRC. The proposal included the existing CRAY C90 (for which the offerors used government performance numbers and is thus not considered in this report), a new 32-node two-chassis Silicon Graphics, Inc. (SGI) Power Challenge Array (PCA), and a new 256-node Cray Research CRAY T3D with a CRAY Y-MP front-end. Table 1.1 shows the dates and system times of 


\begin{tabular}{|l|c|c|}
\hline System & Date & Benchmark Time (s) \\
\hline \hline SGI PCA & $12 / 04 / 95$ & 5004 \\
\hline CRAY T3D & $05 / 04 / 95$ & 6338 \\
\hline \hline Measured Benchmark Time & 6338 \\
\hline
\end{tabular}

Table 1.1: NRC proposal benchmark times.

the final submitted benchmarks for each new system, along with the reported Measured Benchmark Time. The benchmark process executed by the offeror used the same model CRAY T3D and PCA proposed in Tab 4 of the proposal in addition to the CRAY C90, which was paper benchmarked as proscribed in the RFP, Attachment VI, paragraph 17. Pre-award benchmarks for the CRAY T3D were run at Cray Research, Inc., in Eagan, MN. PCA benchmarks were run at SGI in Mountain View, CA.

The RFP called for the installed MSRC systems to be re-benchmarked to ensure that the level of performance in the delivered configuration would match the performance of the proposed configuration. Nominally, this process consists of executing the benchmarks as submitted with the final pre-award proposal. However, this process is somewhat complicated in the WES case because the installed PL1 configuration differs from the proposed solution. Through the Engineering Change Proposal mechanism in the contract, the contractor substituted new computational technology, a CRAY T3E, for the proposed CRAY T3D (the remaining hardware is as proposed). The implications of this change to the benchmarking evaluation process and its impact on government acceptance of the installed PL1 configuration will be discussed in the CRAY T3E section of this report. First, the more straightforward benchmark and analysis for the installed PCA are discussed. 


\section{Chapter 2}

\section{SGI Power Challenge Array}

\subsection{System Configuration}

The proposed and installed PCA systems are the same; the system is composed of two HiPPIconnected $^{1}$ chassis each containing sixteen $90 \mathrm{MHz}$ R8000 MIPS processors with a 4 MByte secondary instruction/data cache, a 16 KByte data cache, a 16 KByte instruction cache, and 8192 MBytes of 8-way interleaved memory. The operating system is IRIX 6.2. Detailed information on the components in each chassis can be found in the system configuration tables in Appendix A.

\subsection{Witnessed Benchmark}

For minimal impact on MSRC operations, each chassis of the PCA was benchmarked separately. This posed no technical problems as the offeror did not spread any single iteration of a benchmark over processors in both chassis, effectively allowing the systems to be separated and each chassis benchmarked separately. The benchmark for the first chassis, PCA1, was performed on January 29, 1997 in the Joint Computing Facility of Building 8000 at WES beginning at 13:37 and ending at 15:16. The benchmark for the second chassis, PCA2, was performed on January 31, 1997 at the same location beginning at 13:35 and ending at 14:57. In each case Mitch Baker of NRC executed the benchmark which was witnessed by V. Sotler, J. West, and A. Carrillo, each government employees of WES.

At the beginning of each session, the NRC representative demonstrated the configuration of the system and that all directories and environment variables contained only expected data. The benchmark script was then started, beginning execution of the benchmark suite. During execution government personnel monitored the system to ensure that all processing rules were followed. Following execution the NRC representative generated a $4 \mathrm{~mm}$ DAT tape containing all relevant information. These tapes were then transferred to the government for analysis.

\section{$2.3 \quad$ Results}

The data on the DAT tapes (two tapes, one for each chassis) were then examined to ensure that the rules and guidelines set forth in Attachment VI for benchmark processing and reporting were

\footnotetext{
${ }^{1} \mathrm{HiPPI}$ is the acronym for High Performance Parallel Interface, a network technology which supports high bandwidth connections between closely-coupled computers.
} 


\begin{tabular}{|l|c|c|c|}
\hline Benchmark & Required Iterations & PCA1 & PCA2 \\
\hline \hline 01 & $13+$ & 5 & 5 \\
\hline 02 & $12 \ddagger$ & 0 & 6 \\
\hline 03 & 20 & 20 & 0 \\
\hline 23 & 9 & 4 & 5 \\
\hline 24 & 11 & 11 & 0 \\
\hline 25 & 44 & 44 & 0 \\
\hline 27 & 35 & 0 & 35 \\
\hline 30 & 24 & 24 & 0 \\
\hline 31 & 5 & 3 & 2 \\
\hline
\end{tabular}

$\ddagger$ Balance of required iterations run on the C90

Table 2.1: Benchmark iterations for each chassis.

\begin{tabular}{|l|c|c|}
\hline Chassis & Date & Benchmark Time (s) \\
\hline \hline PCA1 & $01 / 29 / 97$ & 5581 \\
\hline PCA2 & $01 / 31 / 97$ & 4902 \\
\hline \hline System Benchmark Time & 5581 \\
\hline
\end{tabular}

Table 2.2: Power Challenge Array witnessed benchmark times.

followed. The government determined that in each case NRC ran the same benchmarks, in the same order, in the witnessed configuration as in the final pre-award proposal. Table 2.1 shows what these benchmarks were and that the proper number of iterations (as set forth in Attachment VI) of each were performed.

NRC did not deviate from the code changes submitted in the final proposal, and correctness criteria for each benchmark were met. In general, NRC performed the witnessed benchmark in accordance with all rules and met all requirements. In particular, no hardware or software (configuration) changes were made during the benchmark suite execution on either chassis, and neither machine was rebooted, reconfigured, or reinitialized at any time during the measured benchmark process. Table 2.2 shows the benchmark times for each chassis, and the reported system time.

There are some inconsistencies which need to be discussed. First, the pre-award proposal reported a time of 5004 seconds elapsed time for the PCA system (longest time for both chassis). The witnessed benchmark execution time was 5581 seconds. The tables in Appendix A show the percentage difference between the proposed and witnessed execution times for each iteration of each benchmark. Figures 2.1 and 2.2 show the start and stop times for each iteration for both the pre-award proposal and the witnessed benchmark runs (in these figures the y-axis quantity is derived by concatenating the benchmark number with individual iteration numbers; thus, the times for BM31 iteration 5 appear on the y-axis at 31.5). Analysis of these graphs and tables shows that the majority of the benchmark iterations run longer in the witnessed configuration than the proposed configuration, some by as much as $14 \%$ (BM01). However, these are wall clock times, and as such are tremendously sensitive. It is not uncommon to see variations of several percent in wall clock times between back-to-back executions of the same code; in this case the situation 
is further complicated by variations in software versions (the contractor is required to provide the latest versions of compilers and operating system software upon installation; in the time between the final pre-award proposal and installation, several software products transitioned from beta to production versions) and the vagaries of machine configuration. It is thus difficult to establish a direct causal relationship between a particular circumstance and the increased benchmark time for this system. In this regard, however, it is useful to recall that the RFP states that the offeror is rated only on the Measured Benchmark Time, reported as the longest time among all of the measured HPC systems. The proposal indicates that this time is 6338 seconds (achieved by the CRAY T3D). The reported PCA time of 5581 seconds, while longer than the time of 5004 seconds reported in the proposal for the same system, is still significantly less than the Measured Benchmark Time for the MSRC.

Second, an anomaly was found in the execution of BM27 on PCA2. The session log shows a duration of 2 seconds for the edit/compile/link (ECL) stage during the witnessed benchmark, while the time reported in the proposal for the same events is 256 seconds. Further investigation of the ECL log found in SRC/WORK.N.20_x.chas.02/BM27 revealed that, when an attempt was made to compile the application, the file BM27.exe was already present. A listing of that file from the witnessed benchmark tape shows that the program was in fact compiled the morning of the benchmark as follows:

393632 Jan 31 10:47 BM27.exe*

As the benchmark session did not start until 13:30 on that day, it is clear that this program was compiled before the witnessed session. All other benchmark ECL stages were executed properly, and close examination revealed that all other required files for this benchmark (output, etc.) were created in the correct time frame. It is thought that this executable was left as an oversight from a test run conducted the morning before the witnessed benchmark. The benchmark staging order table for PCA2 in Appendix A shows that BM27 is the last benchmark staged on this system. Addition of the compile time for this benchmark (approximately 254 additional seconds from information given in benchmark iteration comparison table in Appendix A) would result in delaying the completion time for this benchmark by approximately four minutes for a final time on this chassis of approximately 5156 seconds - still less than the time for PCA1.

Finally, the I/O benchmark reported in the proposal achieved a transfer rate of $112.28 \mathrm{MByte} / \mathrm{sec}$ using two iterations (one per chassis) and 3200 MByte files. The witnessed transfer rate on the installed system was $87.67 \mathrm{MByte} / \mathrm{sec}$. Section C.5.1.1.2.4, Disk Subsystems, of the RFP requires that the "aggregate data transfer rate across all disk subsystems on each HPC computer system...shall be a minimum of $100 \mathrm{MByte} / \mathrm{sec}$." In this instance the I/O benchmark does not demonstrate satisfaction of this minimum mandatory requirement, a situation which must be addressed by the contractor.

\subsection{Recommendations}

There are several technical concerns which must be addressed before we recommend the SGI Power Challenge Array component of the MSRC target configuration benchmark as successfully completed. First, subject to further discussion, the I/O benchmark should be rerun to demonstrate that the system can achieve a $100 \mathrm{MByte} / \mathrm{sec}$ transfer rate as required in Section C.5.1.1.2.4 of the RFP. Second, the government must evaluate the contractor's explanation for the longer than 


\section{PCA1 Benchmark Staging}

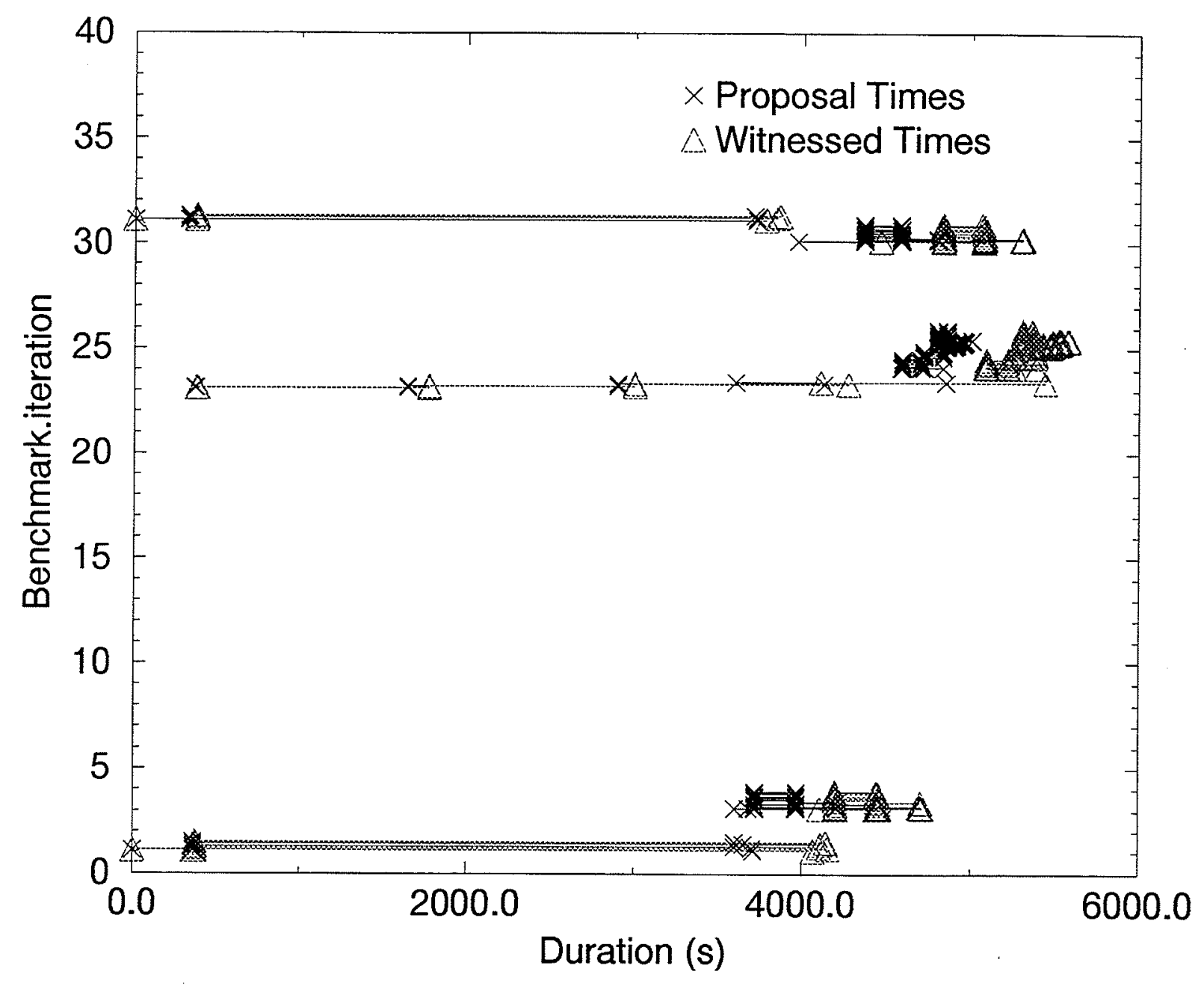

Figure 2.1: PCA1 proposed and witnessed benchmark staging and duration. 


\section{PCA2 Benchmark Staging}

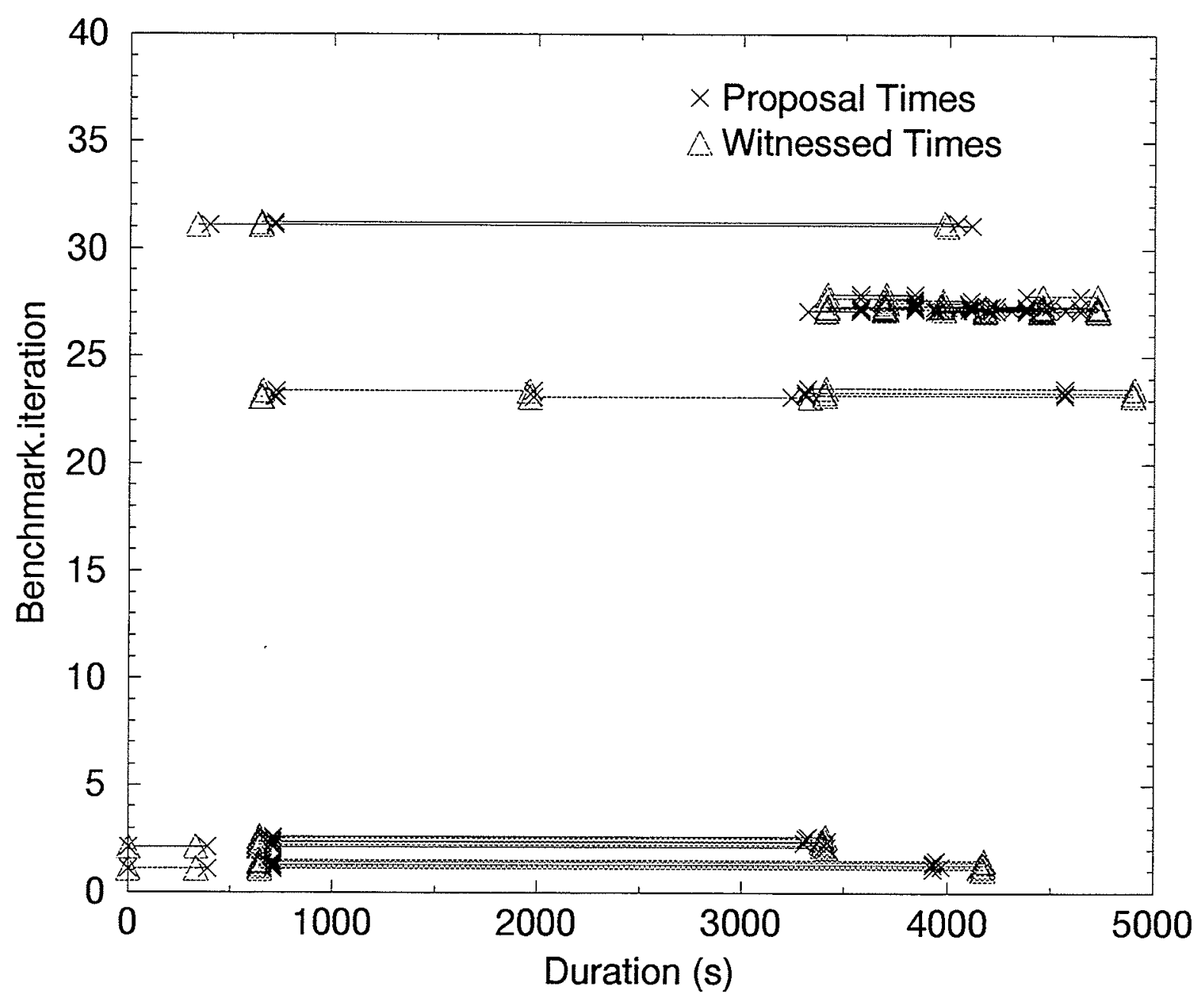

Figure 2.2: PCA2 proposed and witnessed benchmark staging and duration. 
proposed run time of the witnessed benchmark on this system. Finally, the government must have the opportunity to witness the execution of a single iteration of BM27 to resolve questions over the origin of the executable for this benchmark. 


\section{Chapter 3}

\section{CRAY T3E}

\subsection{System Configuration}

As discussed in the introduction, the offeror did not propose or provide benchmark data for a CRAY T3E in the original proposal. The proposed system was a 256-node CRAY T3D with a CRAY Y-MP front-end. This system was substituted after award with an 80-node CRAY T3E (in fact, the installed system is a 256-node CRAY T3E, but only 80 of those nodes were subject to PL1 benchmarking). A detailed listing of hardware components for this system can be found in Appendix B, along with a listing from the proposal specifying the configuration of the proposed CRAY T3D.

The 80-node CRAY T3E was determined to be "equivalent" to a 256-node CRAY T3D by the contractor based on efficiency factors for the processors in each machine. The CRAY T3D has a peak processing capability of 0.15 GFLOPs per processor; through the benchmarking process NRC determined that the peak performance obtained on the government's workload (as represented by the benchmark suite) was 0.0225 GLOPs per processor, an efficiency of $0.0225 / 0.15=0.15$. The vendor reports a peak performance of each CRAY T3E processor as 0.5 GLOPs, or a factor of three beyond the CRAY T3D processors. NRC then assumed the same efficiency factor of 0.15 for the government's workload on the CRAY T3E, and found an estimated sustained performance on the government's workload of 0.075 GLOPs per processor. The difference in projected sustained performance between these machines is thus approximately a factor of three, yielding a rough equivalence of 256 CRAY T3D nodes to 80 CRAY T3E nodes.

The substitution is found to be technically rational given the stated assumptions, though it does create potential complications for the benchmarking of the installed PL1 configuration. The largest potential complication arises from the fact that the proposed MSRC configuration performance was evaluated using the code changes and associated performance for the CRAY T3D system. If code changes on the new CRAY T3E deviated substantially in complexity from those submitted on the CRAY T3D, the issue of relative valuation versus the original would have to be addressed. As shown below, however, there were no substantial code changes made to the proposed CRAY T3D benchmarks in preparation for execution on the CRAY T3E.

One technical issue with the CRAY T3E hardware did arise during the benchmarking process. There is a known problem with the "streams" software interface. Under certain conditions this problem can cause processors to access old copies of data recently updated, leading to computation errors and, in some cases, to a deadlock of the entire machine. The current vendor solution to this problem is to disable the streams interface entirely, which subsequently reduces data access speed 


\begin{tabular}{|l|c|c|}
\hline Benchmark & Required Iterations & CRAY T3E \\
\hline \hline 05 & 10 & 10 \\
\hline 06 & 3 & 3 \\
\hline 20 & 22 & 22 \\
\hline 21 & 5 & 5 \\
\hline 29 & 13 & 13 \\
\hline \multicolumn{2}{|l|}{ System Benchmark Time } & 6317 \\
\hline
\end{tabular}

Table 3.1: Benchmark iterations for the CRAY T3E and measured time.

and can adversely affect performance. As a result, NRC was required to run the benchmark suite with the machine in the "streams disabled" mode.

\subsection{Witnessed Benchmark}

The benchmark for the CRAY T3E system was performed on February 28, 1997 in the Joint Computing Facility of Building 8000 at WES beginning at 10:21 and ending at 13:25. Dave Anderson of Cray Research executed the benchmark for NRC, which was witnessed by V. Sotler, a government employee of WES.

At the beginning of the session the NRC representative demonstrated the configuration of the system and that all directories, environment variables, and file systems contained only expected data. The benchmark script was then started, loading all iterations and compile operations into the system queue. The queue was then started, beginning execution of the benchmark suite. During execution, government personnel monitored the system to ensure that all processing rules were followed. Following execution the NRC representative generated a tar file which was subsequently archived on the MSRC's mass storage system. A 4mm DAT tape was made of this information for archival purposes.

\subsection{Results}

These data were then examined to ensure that the rules and guidelines set forth in Attachment VI for benchmark processing and reporting were followed. NRC ran the same benchmarks in the witnessed configuration as in the final proposal. Table 3.1 shows what these benchmarks were and that the proper number of iterations (as set forth in Attachment VI) of each were performed.

During the witnessed benchmark, no hardware or software (configuration) changes were made during the benchmark suite execution, and the machine was not rebooted, reconfigured, or reinitialized at any time during the measured benchmark process. Furthermore, all benchmark results satisfied their correctness criteria. However, no evidence was found in the submitted benchmark data that the I/O benchmark was executed; this data is required. Table 3.1 shows that the reported system time, 6317 seconds, is less than the proposal time of 6338 seconds. Figure 3.1 shows the start and stop times for each iteration for both the proposal and the witnessed benchmark runs.

During analysis of the benchmark data, it was found that NRC did deviate somewhat from the code changes submitted in the final proposal. This was anticipated given substitution of a CRAY T3E for the CRAY T3D. These changes, detailed in sections 3.3.1 through 3.3.3, are not viewed as 
particularly numerous or complex, and do not add to the overall complexity of modifications to the codes or their achievability by a "typical" researcher. However, some of the changes, particularly to BM20, BM21, and BM29 appear to be solely for the purpose of added optimization and not directed at porting the code to a new architecture. The contractor must supply a justification and explanation for these changes and assess their impact on code performance.

There is one final area of concern. In analysis of the supplied benchmark session log found in the file cewes_t3e.2.script, an apparent error in compilation of BM29 was discovered. Specifically:

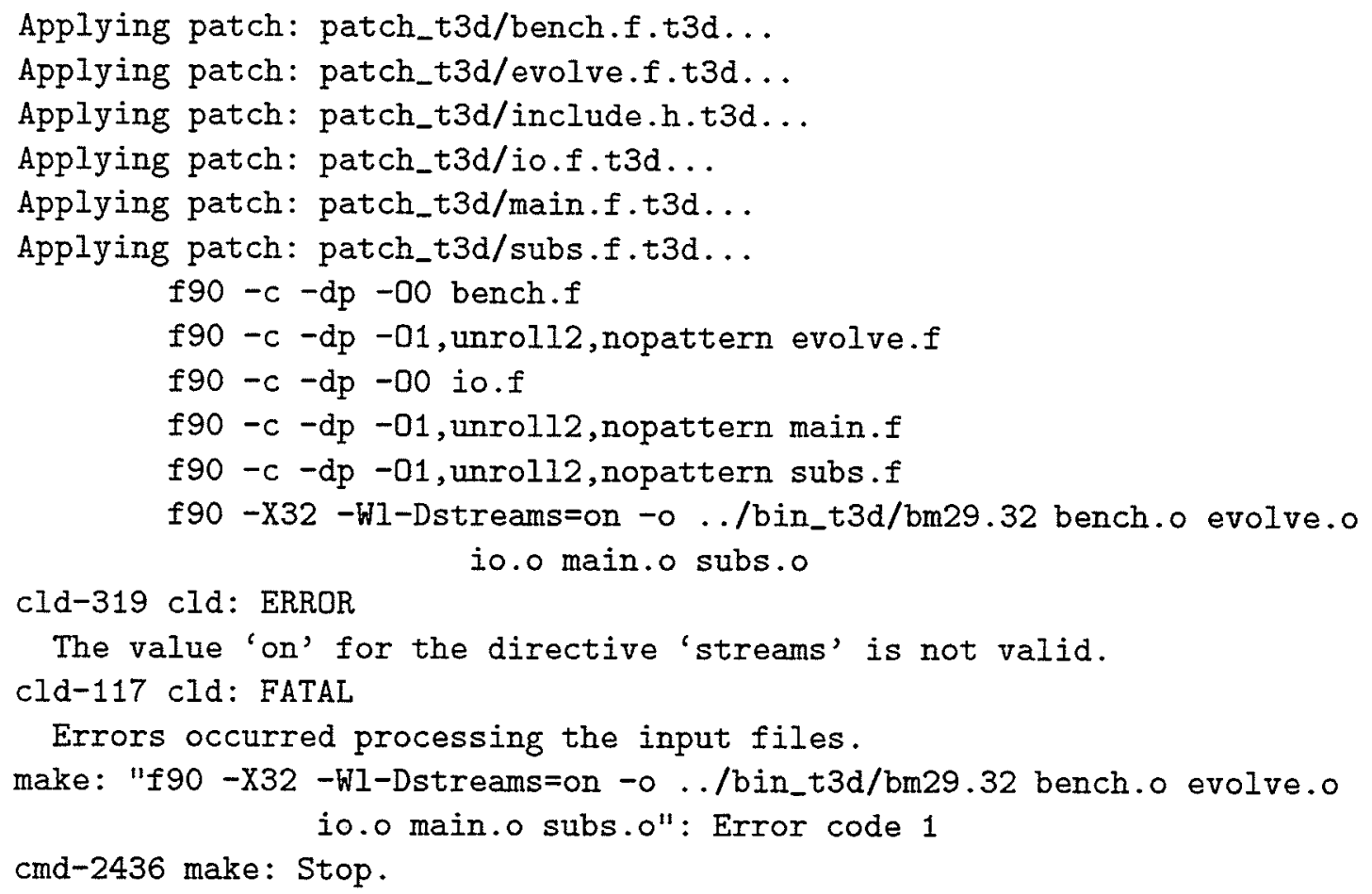

This error causes concern for three reasons. First, the indication in the script of a failed compilation raises questions over the origin of the executable used to run the benchmark. Second, the directive which caused the failed compilation seems designed to activate streams, which must be off for the witnessed benchmark of this system. Finally, it represents a discrepancy between the script file which (presumably) recorded all output of the benchmark session (cewes_t3e.2.script), and the remainder of the logs and supporting data provided for BM29. None of this supporting data indicates a failed compilation or the use of the failed loader directive. The contractor must provide an explanation for this discrepancy.

\subsubsection{BM05 and BM06 Changes}

The only modifications to this benchmark from those submitted for the CRAY T3D were to the routine Admin_Luns.f. This routine is used to coordinate the assignment of logical unit identifiers for file processing, and has no effect on the order of computation or on run times. The changes converted the original code segment from a single routine with multiple entry points to multiple routines (each with a single entry point). Also, an external declaration was removed for the function PvmMin. 


\section{T3E Benchmark Staging}

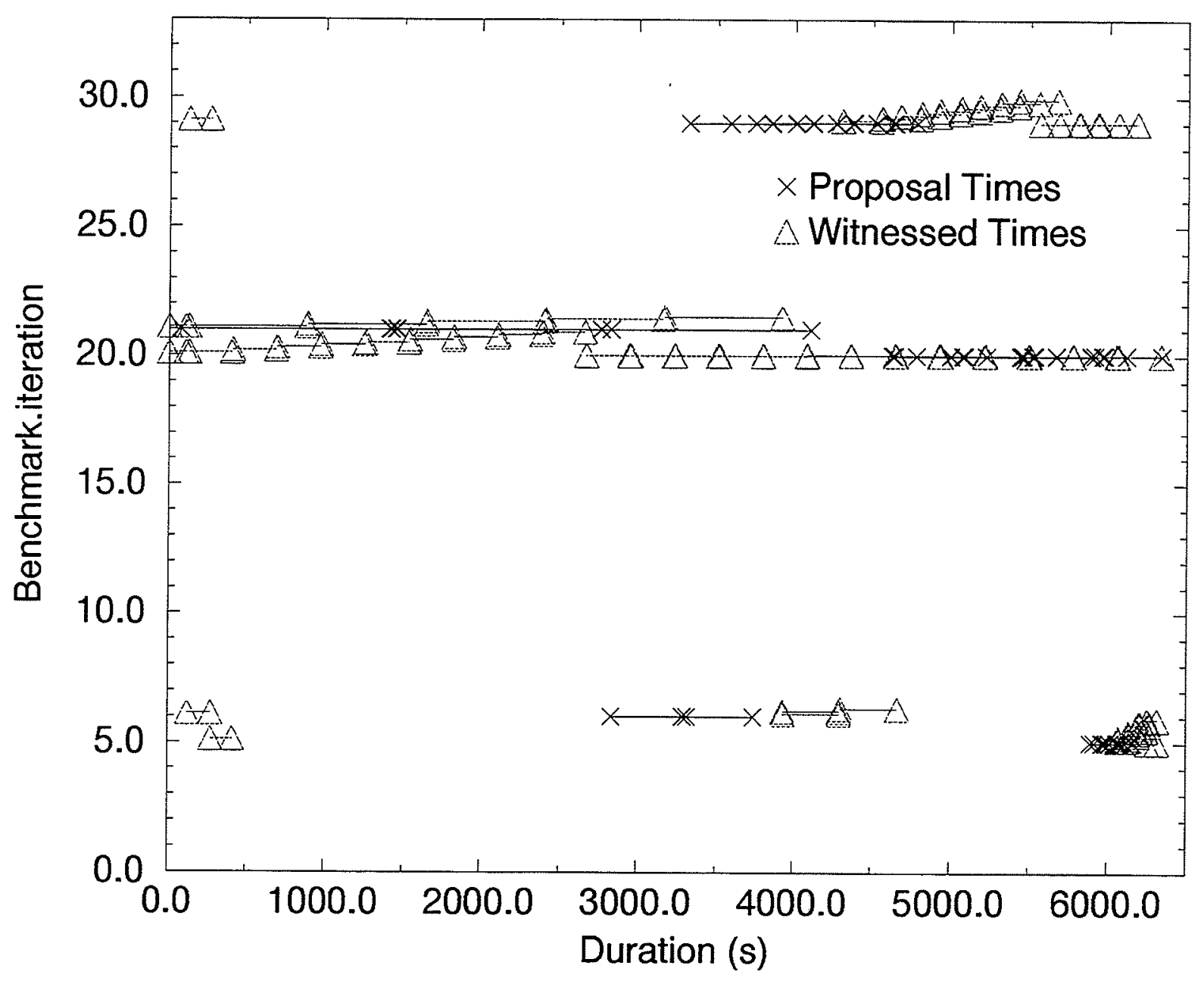

Figure 3.1: CRAY T3D (proposed) and CRAY T3E (witnessed) benchmark staging and duration. 


\subsubsection{BM20 and BM21 Changes}

The only modification to this benchmark for the CRAY T3E was separation of the routine MHMTB0 into its own file (MHMTB0.F).

\subsubsection{BM29}

The primary modifications to this benchmark from those proposed for the CRAY T3D involved changes due to memory size. Various memory variables in bench.f (mem-pe, 1 change) and main.f (various statements, 5 changes) were doubled. Also, the inner loop (dimension 14) of the subroutine equilibrate (found in the file evolve.f) was unrolled 14 times.

\subsection{Recommendations}

There are several technical concerns which must be addressed before we recommend the CRAY T3E component of the MSRC target configuration benchmark as successfully completed. The Measured Benchmark Time for the CRAY T3E is under the proposal MSRC Benchmark Time, and the changes made to the benchmark suite beyond those proposed for the CRAY T3D are few and relatively straightforward. In general, the modifications do not appear to introduce any significant changes in the way the code was executed (memory models, etc.) or in the complexity of the resulting codes. However, the government must have the opportunity to review the contractor's explanation and justification for these changes, as they seem to be focused primarily on performance rather than porting. Also, evidence of I/O benchmark execution on this system was not found; such evidence is required and must be supplied by the contractor before final acceptance of this system. Finally, an explanation of the discrepancy between the session log file and the supporting data for BM29 must be provided, and the government must witness the execution of a single iteration of this benchmark to resolve questions over the origin of its executable. 


\section{Chapter 4}

\section{Summary and Recommendations}

The witnessed benchmark of the contractor-installed WES PL1 HPC target configuration has been completed. The contractor proposed an HPC target configuration consisting of a 32-processor SGI Power Challenge Array, a 256-processor CRAY T3D, and a 16-processor CRAY C90. Through the Engineering Change Proposal process, the CRAY T3D component of the configuration was replaced with an 80-processor CRAY T3E. The impact of the substitution of the CRAY T3E on code changes has been assessed and appears to be minimal. Furthermore, the Measured Benchmark Time of the installed configuration, 6317 seconds, is less than the time for the proposed configuration, 6338 seconds.

Analysis of the supplied benchmark data indicates that several concerns must be addressed before the benchmark can be recommended as successfully completed. A detailed discussion of these concerns and the issues surrounding them may be found in the preceding chapters.

\section{Power Challenge Array}

- The I/O benchmark for SGI Power Challenge Array must be rerun to demonstrate that the system can achieve the $100 \mathrm{MByte} / \mathrm{sec}$ transfer rate required in Section C.5.1.1.2.4 of the RFP.

- The government must have the opportunity to witness the execution of a single iteration of BM27 to resolve questions over the origin of the executable for this benchmark.

- A written explanation for the longer than proposed run time of the witnessed Power Challenge Array Benchmark must be provided for further assessment.

\section{CRAY T3E}

- Although the changes made to the benchmarks for the CRAY T3E are few and are not found to introduce significant new complexity, they seem primarily directed to performance enhancements and not porting issues. The contractor must provide an explanation and justification for these changes.

- Evidence of I/O benchmark execution on the CRAY T3E was not found; such evidence is required and must be supplied by the contractor before final acceptance of this system. 
- There is a discrepancy between the session log file which recorded the full details of the entire benchmark process and the supporting data and individual logs for BM29. The session log indicates a failed compilation due to a streams variable, while the individual for BM29 does not indicate a problem. The contractor must provide an explanation of this discrepancy:

- The government must have the opportunity to witness the execution of a single iteration of BM29 to resolve questions over the origin of the executable for this benchmark. 

Appendix A

Supporting Data: Power Challenge Array 


\section{A.1 PCA1 Configuration}

The following is selected output from the sysconf command executed on PCA1.

VENDOR
OS_PROVIDER
OS_NAME
HW_NAME
NUM_PROCESSORS
HOSTID
OSREL_MAJ
OSREL_MIN
OSREL_PATCH
PROCESSORS

AVAIL_PROCESSORS
SYSNAME
HOSTNAME
RELEASE
VERSION
ACHINE
ARCHITECTURE
HW_SERIAL
HW_PROVIDER
SRPC_DOMAIN
INITTAB_NAME

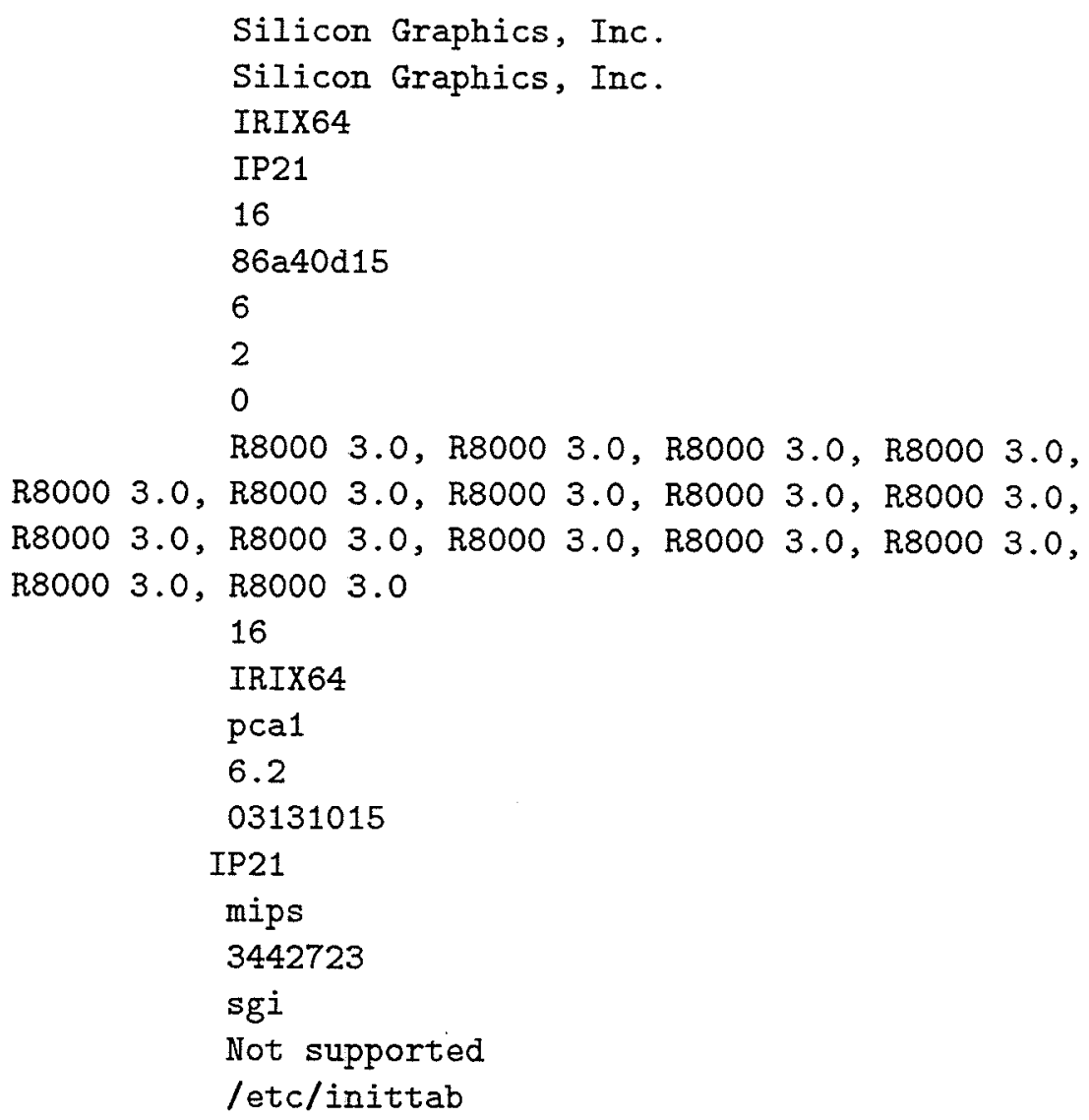

The following information is extracted from the output of the hinv command executed on PCA1.

$1690 \mathrm{MHZ}$ IP21 Processors

CPU: MIPS R8000 Processor Chip Revision: 3.0

FPU: MIPS R8010 Floating Point Chip Revision: 0.2

Secondary unified instruction/data cache size: 4 Mbytes

Data cache size: 16 Kbytes

Instruction cache size: 16 Kbytes

ain memory size: 8192 Mbytes, 8-way interleaved

I/O board, Ebus slot 11: I04 revision 1

I/O board, Ebus slot 15: I04 revision 1

Integral EPC serial ports: 4

Integral Ethernet controller: eto, Ebus slot 15

XPI FDDI controller: xpi0, slot 11, adapter 13, firmware version 9603091500 , DAS 


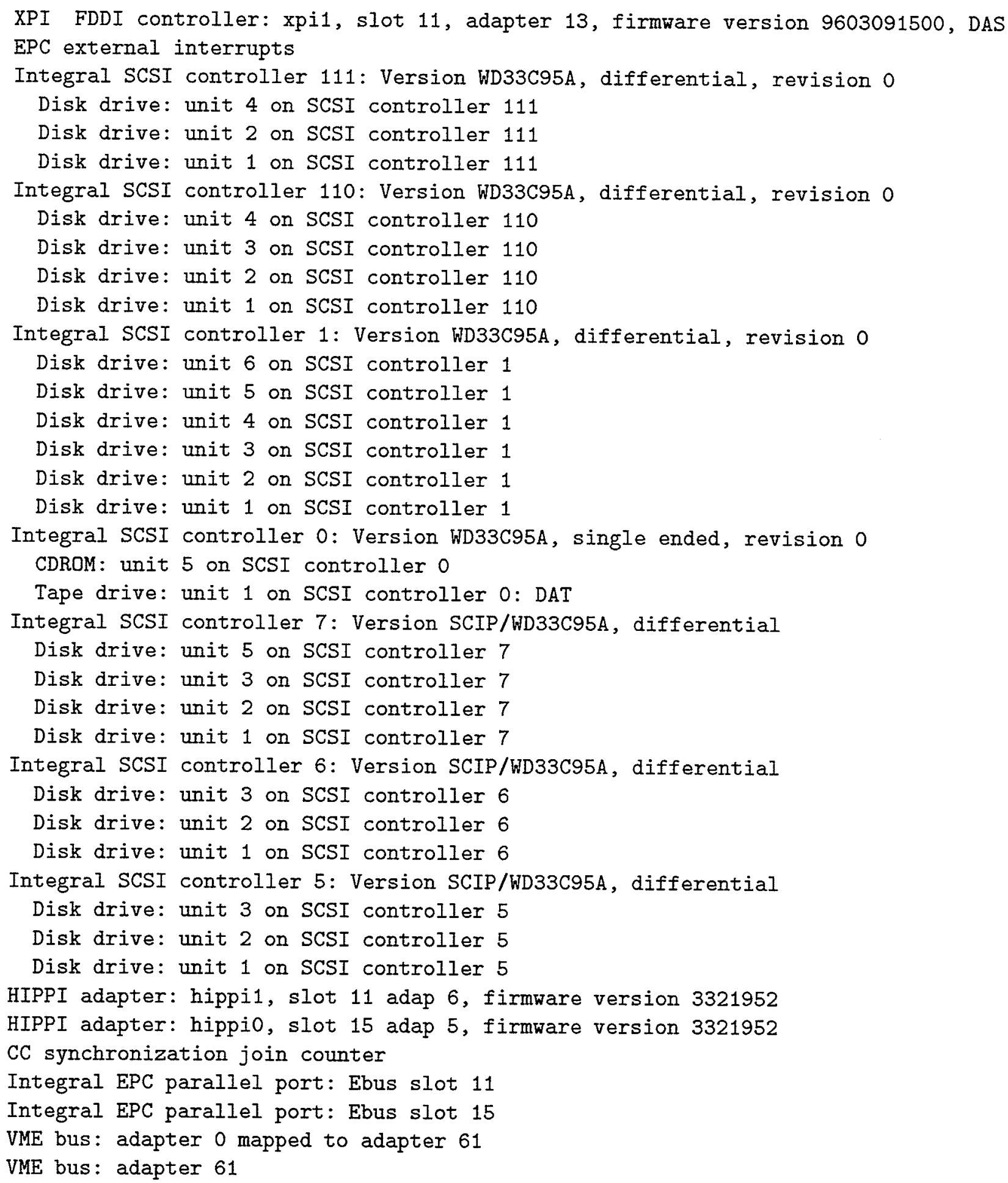

The following compilers were proposed and used to run the original benchmarks (selected output of the versions command): 

I $f \operatorname{tn} 77_{-} \mathrm{dev}$
10/13/95 Fortran 77, 6.1
I ftn90_dev
10/13/95 Fortran 90, 6.2ALPHA
I c_dev
$10 / 13 / 95$ C, 6.2 ALPHA

The following compilers are installed and used to run the witnessed benchmarks (selected output of the versions command):
I $\mathrm{ftn} 77_{-} \mathrm{dev}$
I ftn90_dev
I c_dev
01/23/97 Fortran 77, 6.2
01/09/97 Fortran 90, 7.1 on irix 6.2
$01 / 23 / 97$ C, 6.2




\section{A.2 PCA2 Configuration}

The following is selected output from the sysconf command executed on PCA2.

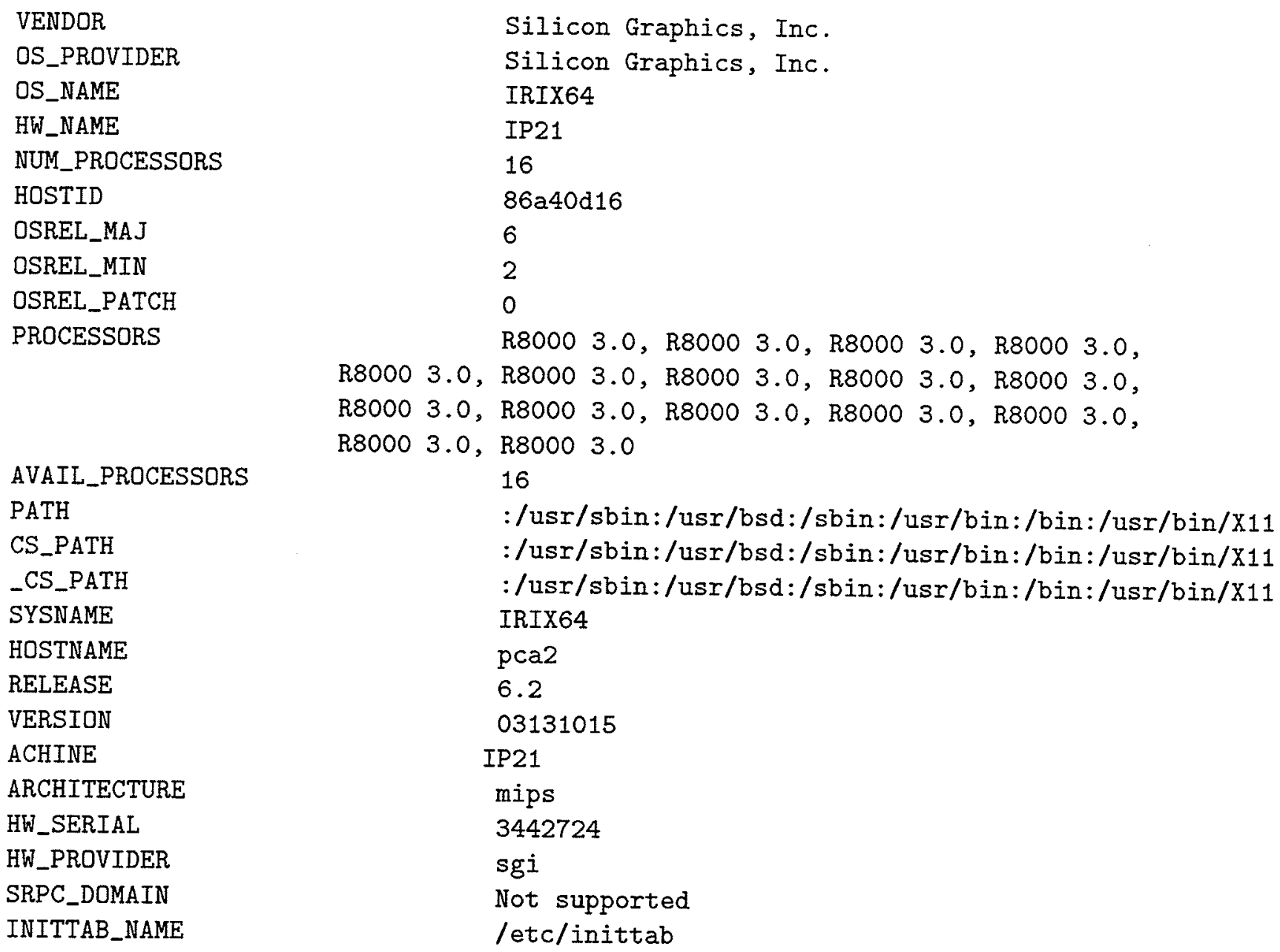

The following information is extracted from the output of the hinv command executed on PCA2.

1690 MHZ IP21 Processors

CPU: MIPS R8000 Processor Chip Revision: 3.0

FPU: MIPS R8010 Floating Point Chip Revision: 0.2

Secondary unified instruction/data cache size: 4 Mbytes

Data cache size: 16 Kbytes

Instruction cache size: 16 Kbytes

ain memory size: 8192 Mbytes, 8-way interleaved

I/O board, Ebus slot 13: I04 revision 1

I/O board, Ebus slot 15: IO4 revision 1 
Integral EPC serial ports: 4

Integral Ethernet controller: eto, Ebus slot 15

XPI FDDI controller: xpi0, slot 13, adapter 13, firmware version 9603091500, DAS

XPI FDDI controller: xpi1, slot 13, adapter 13, firmware version 9603091500 , DAS EPC external interrupts

Integral SCSI controller 131: Version WD33C95A, differential, revision 0

Disk drive: unit 4 on SCSI controller 131

Disk drive: unit 3 on SCSI controller 131

Disk drive: unit 2 on SCSI controller 131

Disk drive: unit 1 on SCSI controller 131

Integral SCSI controller 130: Version WD33C95A, differential, revision 0

Disk drive: unit 3 on SCSI controller 130

Disk drive: unit 2 on SCSI controller 130

Disk drive: unit 1 on SCSI controller 130

Integral SCSI controller 1: Version WD33C95A, differential, revision 0

Disk drive: unit 4 on SCSI controller 1

Disk drive: unit 3 on SCSI controller 1

Disk drive: unit 2 on SCSI controller 1

Disk drive: unit 1 on SCSI controller 1

Integral SCSI controller 0: Version WD33C95A, differential, revision 0

Disk drive: unit 4 on SCSI controller 0

Disk drive: unit 3 on SCSI controller 0

Disk drive: unit 2 on SCSI controller 0

Disk drive: unit 1 on SCSI controller 0

Integral SCSI controller 4: Version SCIP/WD33C95A, differential

Disk drive: unit 3 on SCSI controller 4

Disk drive: unit 2 on SCSI controller 4

Disk drive: unit 1 on SCSI controller 4

Integral SCSI controller 3: Version SCIP/WD33C95A, differential

Disk drive: unit 3 on SCSI controller 3

Disk drive: unit 2 on SCSI controller 3

Disk drive: unit 1 on SCSI controller 3

Integral SCSI controller 2: Version SCIP/WD33C95A, differential

Disk drive: unit 3 on SCSI controller 2

Disk drive: unit 2 on SCSI controller 2

Disk drive: unit 1 on SCSI controller 2

HIPPI adapter: hippi1, slot 13 adap 6, firmware version 3321952

HIPPI adapter: hippio, slot 15 adap 6, firmware version 3321952

CC synchronization join counter

Integral EPC parallel port: Ebus slot 13

Integral EPC parallel port: Ebus slot 15

VME bus: adapter 0 mapped to adapter 61

VME bus: adapter 61

The following compilers were proposed and used to run the original benchmarks (selected output of the versions command): 
I $f \operatorname{tn} 77_{-} \mathrm{dev}$

I ftn90_dev

I c_dev
10/13/95 Fortran $77,6.1$

10/13/95 Fortran 90, 6.2ALPHA

10/13/95 C, 6.2ALPHA

The following compilers are installed and used to run the witnessed benchmarks (selected output of the versions command):

I ftn77_dev
I ftn90_dev
I c_dev
$01 / 23 / 97$ Fortran $77,6.2$

$01 / 09 / 97$ Fortran $90,7.1$ on irix 6.2

$01 / 23 / 97$ C, 6.2 


\section{A.3 PCA1 Benchmark Iteration Comparison}

\begin{tabular}{|c|c|c|c|c|}
\hline \multicolumn{2}{|c|}{ Proposal } & \multicolumn{2}{|c|}{ Witness } & \multirow{2}{*}{$\begin{array}{l}\text { Diff } \\
100 *(\text { wit-prop)/prop }\end{array}$} \\
\hline $\mathrm{BM} /$ Itr : & $t(s)$ & $\mathrm{BM} / \mathrm{Itr}: \mathrm{t}$ & & \\
\hline BM01ECL001 & : 365 & BM01ECL001 & 366 & +0.27 \\
\hline BM01RUN001 & : $\quad 3345$ & BM01RUN001 & 3694 & +10.43 \\
\hline BM01RUNO02 & : 3339 & BM01RUN002 & 3785 & +13.36 \\
\hline BM01RUN003 & : 3233 & BM01RUN003 & 3734 & +15.50 \\
\hline BM01RUN004 & : 3289 & BM01RUN004 & 3741 & +13.74 \\
\hline BM01RUN005 & : $\quad 3235$ & BM01RUN005 & 3773 & +16.63 \\
\hline BM03ECL001 & : 82 & BM03ECL001 & 90 & +9.76 \\
\hline BM03RUN001 & : 243 & BM03RUN001 & 254 & +4.53 \\
\hline BMO3RUNOO2 & : 242 & BM03RUN002 & 245 & +1.24 \\
\hline BM03RUN003 & $: \quad 243$ & BM03RUN003 & 247 & +1.65 \\
\hline BM03RUN004 & : $\quad 241$ & BM03RUN004 & 248 & +2.90 \\
\hline BMO3RUN005 & : $\quad 241$ & BM03RUNO05 & 249 & +3.32 \\
\hline BM03RUN006 & : 244 & BM03RUNO06 & 258 & +5.74 \\
\hline BM03RUN007 & : 243 & BM03RUN007 & 247 & +1.65 \\
\hline BM03RUN008 & $: \quad 244$ & BM03RUN008 & 248 & +1.64 \\
\hline BM03RUN009 & : 244 & BM03RUN009 & 247 & +1.23 \\
\hline BM03RUN010 & : 244 & BM03RUN010 & 245 & +0.41 \\
\hline BM03RUN011 & $: 243$ & BM03RUN011 & 248 & +2.06 \\
\hline BM03RUN012 & : 242 & BM03RUN012 & 245 & +1.24 \\
\hline BM03RUN013 & : 242 & BM03RUN013 & 246 & +1.65 \\
\hline BM03RUN014 & : 242 & BM03RUN014 & 250 & +3.31 \\
\hline BM03RUN015 & : 241 & BM03RUN015 & 247 & +2.49 \\
\hline BM03RUN016 & : $\quad 242$ & BM03RUNO16 & 245 & +1.24 \\
\hline BM03RUN017 & : 243 & BM03RUN017 & 246 & +1.23 \\
\hline BM03RUN018 & : 241 & BM03RUN018 & 247 & +2.49 \\
\hline BM03RUN019 & : $\quad 241$ & BM03RUN019 & 246 & +2.07 \\
\hline BMO3RUNO20 & : $\quad 242$ & BM03RUN020 & 247 & +2.07 \\
\hline BM23ECL001 & $: 8$ & BM23ECL001 & 9 & +12.50 \\
\hline BM23RUNO01 & : 1267 & BM23RUNO01 & 1387 & +9.47 \\
\hline BM23RUNOO2 & : 1257 & BM23RUNOO2 & 1231 & -2.07 \\
\hline BM23RUNOO3 & : 1233 & BM23RUN003 & 1269 & +2.92 \\
\hline BM23RUNOO4 & : $\quad 1246$ & BM23RUNO04 & 1330 & +6.74 \\
\hline BM24ECL001 & $: 6$ & BM24ECL001 & 9 & +50.00 \\
\hline BM24RUNO01 & : 111 & BM24RUN001 & 123 & +10.81 \\
\hline BM24RUNOO2 & : 112 & BM24RUNOO2 & 129 & +15.18 \\
\hline BM24RUNOO3 & : 112 & BM24RUN003 & 123 & +9.82 \\
\hline
\end{tabular}




\begin{tabular}{|c|c|c|c|c|}
\hline BM24RUNOO4 & 112 & BM24RUNOO4 & 126 & +12.50 \\
\hline BM24RUNO05 & 111 & BM24RUNOO5 & 129 & +16.22 \\
\hline BM24RUN006 & 113 & BM24RUNO06 & : 129 & +14.16 \\
\hline BM24RUN007 & 112 & BM24RUNO07 & 129 & +15.18 \\
\hline BM24RUN008 & 111 & BM24RUN008 & 128 & +15.32 \\
\hline BM24RUNO09 & 112 & BM24RUNOO9 & 126 & +12.50 \\
\hline BM24RUN010 & 112 & BM24RUN010 & 128 & +14.29 \\
\hline BM24RUN011 & 114 & BM24RUNO11 & : 129 & +13.16 \\
\hline BM25ECLOO1 & 3 & BM25ECLO01 & 5 & +66.67 \\
\hline BM25RUNO01 & 52 & BM25RUNO01 & $: 56$ & +7.69 \\
\hline BM25RUNOO2 & 53 & BM25RUNO02 & $: \quad 55$ & +3.77 \\
\hline BM25RUNO03 & 52 & BM25RUNO03 & : 56 & +7.69 \\
\hline BM25RUNO04 & 51 & BM25RUNO04 & $: \quad 57$ & +11.76 \\
\hline BM25RUNO05 & 51 & BM25RUNO05 & : 58 & +13.73 \\
\hline BM25RUNOO6 & 53 & BM25RUNO06 & : 58 & +9.43 \\
\hline BM25RUN007 & 54 & BM25RUNO07 & 64 & +18.52 \\
\hline BM25RUN008 & 53 & BM25RUNO08 & 57 & +7.55 \\
\hline BM25RUNOO9 & 52 & BM25RUNO09 & 57 & +9.62 \\
\hline BM25RUN010 & 51 & BM25RUN010 & 51 & +0.00 \\
\hline BM25RUN011 & 52 & BM25RUNO11 & 52 & +0.00 \\
\hline BM25RUN012 & 51 & BM25RUN012 & $: 51$ & +0.00 \\
\hline BM25RUNO13 & 52 & BM25RUN013 & $: \quad 52$ & +0.00 \\
\hline BM25RUN014 & 51 & BM25RUNO14 & 52 & +1.96 \\
\hline BM25RUN015 & 52 & BM25RUN015 & 52 & +0.00 \\
\hline BM25RUN016 & 51 & BM25RUN016 & 51 & +0.00 \\
\hline BM25RUN017 & 51 & BM25RUN017 & 58 & +13.73 \\
\hline BM25RUNO18 & 52 & BM25RUN018 & 52 & +0.00 \\
\hline BM25RUN019 & 52 & BM25RUNO19 & 54 & +3.85 \\
\hline BM25RUNO20 & 52 & BM25RUNO20 & : 53 & +1.92 \\
\hline BM25RUNO21 & 52 & BM25RUNO21 & 52 & +0.00 \\
\hline BM25RUNO22 & 52 & BM25RUNO22 & : 52 & +0.00 \\
\hline BM25RUN023 & 52 & BM25RUN023 & 52 & +0.00 \\
\hline BM25RUNO24 & 52 & BM25RUNO24 & : 53 & +1.92 \\
\hline BM25RUNO25 & 51 & BM25RUNO25 & : 51 & +0.00 \\
\hline BM25RUN026 & 52 & BM25RUNO26 & : 52 & +0.00 \\
\hline BM25RUN027 & 52 & BM25RUN027 & : 52 & +0.00 \\
\hline BM25RUN028 & 52 & BM25RUNO28 & : $\quad 52$ & +0.00 \\
\hline BM25RUNO29 & 52 & BM25RUNO29 & : 52 & +0.00 \\
\hline BM25RUN030 & 51 & BM25RUN030 & : 52 & +1.96 \\
\hline BM25RUNO31 & 51 & BM25RUNO31 & : 52 & +1.96 \\
\hline BM25RUN032 & 51 & BM25RUN032 & $: 53$ & +3.92 \\
\hline BM25RUN033 & 51 & BM25RUN033 & $: \quad 52$ & +1.96 \\
\hline BM25RUN034 & 51 & BM25RUN034 & : 52 & +1.96 \\
\hline BM25RUN035 & 52 & BM25RUN035 & : 52 & +0.00 \\
\hline BM25RUN036 & 51 & BM25RUN036 & $: \quad 52$ & +1.96 \\
\hline
\end{tabular}




\begin{tabular}{|c|c|c|c|c|}
\hline BM25RUN037 & 51 & BM25RUN037 & 52 & +1.96 \\
\hline BM25RUN038 & 51 & BM25RUN038 & 51 & +0.00 \\
\hline BM25RUN039 & 51 & BM25RUN039 & 51 & +0.00 \\
\hline BM25RUNO40 & 51 & BM25RUN040 & 51 & +0.00 \\
\hline BM25RUNO41 & 50 & BM25RUN041 & 51 & +2.00 \\
\hline BM25RUNO42 & 50 & BM25RUNO42 & 51 & +2.00 \\
\hline BM25RUN043 & 51 & BM25RUNO43 & 51 & +0.00 \\
\hline BM25RUNO44 & 51 & BM25RUNO44 & 52 & +1.96 \\
\hline BM30ECL001 & 395 & BM30ECL001 & 370 & -6.33 \\
\hline BM30RUN001 & 213 & BM30RUNO01 & 228 & +7.04 \\
\hline BM3ORUNOO2 & 215 & BM3ORUN002 & 239 & +11.16 \\
\hline BM30RUNO03 & 214 & BM30RUN003 & 233 & +8.88 \\
\hline BM30RUN004 & 215 & BM30RUN004 & 242 & +12.56 \\
\hline BM3ORUNO05 & 215 & BM30RUN005 & 235 & +9.30 \\
\hline BM30RUN006 & 214 & BM30RUNO06 & 240 & +12.15 \\
\hline BM30RUN007 & 216 & BM30RUN007 & 230 & +6.48 \\
\hline BM30RUN008 & 216 & BM30RUNO08 & 241 & +11.57 \\
\hline BM30RUNO09 & 214 & BM30RUN009 & 227 & +6.07 \\
\hline BM30RUN010 & 214 & BM3ORUN010 & 240 & +12.15 \\
\hline BM30RUN011 & 215 & BM30RUNO11 & 240 & +11.63 \\
\hline BM30RUN012 & 216 & BM3ORUN012 & 240 & +11.11 \\
\hline BM30RUN013 & 217 & BM30RUN013 & 231 & +6.45 \\
\hline BM30RUN014 & 216 & BM3ORUN014 & 240 & +11.11 \\
\hline BM30RUN015 & 213 & BM3ORUN015 & 241 & +13.15 \\
\hline BM30RUN016 & 217 & BM30RUN016 & 233 & +7.37 \\
\hline BM30RUN017 & 215 & BM30RUNO17 & 222 & +3.26 \\
\hline BM3ORUN018 & 214 & BM30RUN018 & 227 & +6.07 \\
\hline BM30RUNO19 & 214 & BM3ORUN019 & 224 & +4.67 \\
\hline BM30RUNO20 & 214 & BM3ORUNO20 & 225 & +5.14 \\
\hline BM3ORUNO21 & 214 & BM3ORUNO21 & 223 & +4.21 \\
\hline BM30RUNO22 & 215 & BM3ORUNO22 & 228 & +6.05 \\
\hline BM3ORUNO23 & 215 & BM3ORUN023 & 225 & +4.65 \\
\hline BM3ORUN024 & 215 & BM30RUNO24 & 227 & +5.58 \\
\hline BM31ECL001 & 328 & BM31ECL001 & 374 & +14.02 \\
\hline BM31RUN001 & 3393 & BM31RUN001 & 3406 & +0.38 \\
\hline BM31RUNOO2 & 3394 & BM31RUN002 & 3468 & +2.18 \\
\hline BM31RUN003 & 3382 & BM31RUN003 & 3489 & +3.16 \\
\hline
\end{tabular}




\section{A.4 PCA2 Benchmark Iteration Comparison}

\begin{tabular}{|c|c|c|c|c|}
\hline \multicolumn{2}{|c|}{ Proposal } & \multicolumn{2}{|l|}{ Witness } & \multirow{2}{*}{$\begin{array}{l}\text { Diff } \\
100 *(\text { wit-prop)/prof }\end{array}$} \\
\hline BM/Itr : & $t(s)$ & $\mathrm{BM} / \mathrm{Itr}: \mathrm{t}$ & (s) & \\
\hline BM01ECL001 : & 389 & BM01ECL001 & 332 & -14.65 \\
\hline BM01RUN001 : & 3217 & BM01RUN001 & : 3529 & +9.70 \\
\hline BM01RUN002 : & 3260 & BM01RUNOO2 & : $\quad 3517$ & +7.88 \\
\hline BM01RUN003 : & : $\quad 3218$ & BM01RUN003 & : 3528 & +9.63 \\
\hline BM01RUN004 : & : 3219 & BM01RUN004 & : 3530 & +9.66 \\
\hline BM01RUNO05 : & : 3235 & BM01RUN005 & : 3533 & +9.21 \\
\hline BM02ECLOO1 : & : 389 & BM02ECL001 & 332 & -14.65 \\
\hline BMO2RUNO01 & : $\quad 2706$ & BM02RUNO01 & : 2768 & +2.29 \\
\hline BM02RUNO02 : & : 2696 & BM02RUNO02 & : $\quad 2755$ & +2.19 \\
\hline BM02RUN003 : & : 2594 & BM02RUNOO3 & $: \quad 2756$ & +6.25 \\
\hline BM02RUNO04 : & : 2708 & BMO2RUNO04 & : $\quad 2749$ & +1.51 \\
\hline BM02RUN005 : & : 2606 & BM02RUN005 & 2761 & +5.95 \\
\hline BM02RUN006 & : $\quad 2616$ & BM02RUN006 & : $\quad 2766$ & +5.73 \\
\hline BM23ECL001 : & $: 9$ & BM23ECL001 & $: 8$ & -11.11 \\
\hline BM23RUNO01 : & : 1257 & BM23RUNOO1 & : 1369 & +8.91 \\
\hline BM23RUNOO2 : & : 1259 & BM23RUNOO2 & 1497 & +18.90 \\
\hline BM23RUN003 & : 1260 & BM23RUNO03 & 1497 & +18.81 \\
\hline BM23RUNO04 & : 1260 & BM23RUN004 & 1306 & +3.65 \\
\hline BM23RUNO05 & $: \quad 1248$ & BM23RUNOO5 & 1497 & +19.95 \\
\hline BM27ECL001： & : 256 & BM27ECL001 & $: \quad 2$ & -99.22 \\
\hline BM27RUN001 & $: \quad 260$ & BM27RUNO01 & $: \quad 273$ & +5.00 \\
\hline BM27RUNOO2 & : 261 & BM27RUNOO2 & : 275 & +5.36 \\
\hline BM27RUN003 & : 262 & BM27RUNO03 & 277 & +5.73 \\
\hline BM27RUN004 & : 264 & BM27RUNO04 & : $\quad 276$ & +4.55 \\
\hline BM27RUNO05: & $: 263$ & BM27RUNO05 & $: \quad 281$ & +6.84 \\
\hline BM27RUNO06 & $: \quad 274$ & BM27RUNO06 & $: \quad 277$ & +1.09 \\
\hline BM27RUNOO7 & : 260 & BM27RUN007 & $: \quad 277$ & +6.54 \\
\hline BM27RUN008 & : $\quad 262$ & BM27RUN008 & $: \quad 269$ & +2.67 \\
\hline BM27RUN009 & : $\quad 261$ & BM27RUN009 & : 283 & +8.43 \\
\hline BM27RUN010 & : 260 & BM27RUN010 & : 269 & +3.46 \\
\hline BM27RUN011 & : $\quad 261$ & BM27RUNO11 & : $\quad 271$ & +3.83 \\
\hline BM27RUN012 & $: \quad 263$ & BM27RUN012 & $: \quad 270$ & +2.66 \\
\hline BM27RUN013 & : $\quad 261$ & BM27RUN013 & $: \quad 275$ & +5.36 \\
\hline BM27RUN014 & : $\quad 262$ & BM27RUN014 & : 272 & +3.82 \\
\hline BM27RUNO15 & $: 260$ & BM27RUN015 & : 274 & +5.38 \\
\hline BM27RUN016 & : 262 & BM27RUN016 & : 275 & +4.96 \\
\hline
\end{tabular}




\begin{tabular}{|c|c|c|c|c|}
\hline BM27RUN017 & 260 & BM27RUN017 & 270 & +3.85 \\
\hline BM27RUN018 & 262 & BM27RUN018 & 273 & +4.20 \\
\hline BM27RUN019 & 261 & BM27RUN019 & 274 & +4.98 \\
\hline BM27RUNO20 & 262 & BM27RUNO20 & 274 & +4.58 \\
\hline BM27RUN021 & 280 & BM27RUNO21 & 280 & +0.00 \\
\hline BM27RUNO22 & 265 & BM27RUNO22 & 280 & +5.66 \\
\hline BM27RUNO23 & 260 & BM27RUNO23 & 274 & +5.38 \\
\hline BM27RUNO24 & 261 & BM27RUNO24 & 272 & +4.21 \\
\hline BM27RUNO25 & 261 & BM27RUNO25 & 272 & +4.21 \\
\hline BM27RUN026 & 261 & BM27RUN026 & 270 & +3.45 \\
\hline BM27RUNO27 & 261 & BM27RUNO27 & 275 & +5.36 \\
\hline BM27RUN028 & 260 & BM27RUNO28 & 270 & +3.85 \\
\hline BM27RUN029 & 261 & BM27RUNO29 & 270 & +3.45 \\
\hline BM27RUN030 & 261 & BM27RUN030 & 271 & +3.83 \\
\hline BM27RUN031 & 260 & BM27RUN031 & 269 & +3.46 \\
\hline BM27RUN032 & 269 & BM27RUN032 & 276 & +2.60 \\
\hline BM27RUN033 & 261 & BM27RUN033 & 279 & +6.90 \\
\hline BM27RUN034 & 261 & BM27RUN034 & 269 & +3.07 \\
\hline BM27RUN035 & 260 & BM27RUN035 & 270 & +3.85 \\
\hline BM31ECL001 & 319 & BM31ECL001 & 310 & -2.82 \\
\hline BM31RUN001 & 3403 & BM31RUN001 & 3347 & -1.65 \\
\hline BM31RUNO02 & 3331 & BM31RUNOO2 & 3336 & +0.15 \\
\hline BM31RUN002 & 3336 & BM31RUNOO2 & 3336 & +0.00 \\
\hline
\end{tabular}




\title{
A.5 PCA1 Benchmark Staging Order
}

The following is a selection of text from the script which controls the execution order of each benchmark iteration to be run on this chassis. Benchmarks in the witnessed configuration were staged in the same order as those in the proposal.

\begin{abstract}
alljobs = BM31ECL001 BM01ECL001 BM31RUN001 BM31RUN002 BM31RUNO03
BM01RUN003 BM01RUNO04 BM01RUN001 BM01RUN002 BM01RUNO05 BM23ECL001

BM23RUN001 BM23RUNO02 BM23RUN003 BM23RUN004 BM03ECL001 BM03RUN003

BM03RUNO01 BM03RUNO02 BM03RUN005 BM03RUN006 BM03RUN007 BM03RUN008

BM03RUN009 BM03RUN010 BM03RUN011 BM03RUN012 BM03RUN013 BM03RUN016

BM03RUN017 BM03RUN018 BM03RUN019 BM03RUNO20 BM03RUN004 BM03RUN014

BMO3RUN015 BM3OECLO01 BM3ORUNO01 BM3ORUNO02 BM3ORUNO03 BM3ORUNO04

BM3ORUNO05 BM3ORUNO06 BM30RUNO07 BM30RUNO08 BM3ORUNO09 BM3ORUNO10

BM3ORUN011 BM3ORUN012 BM3ORUN013 BM3ORUN014 BM3ORUNO15 BM3ORUNO16

BM3ORUNO17 BM3ORUNO18 BM3ORUNO19 BM3ORUNO20 BM3ORUNO21 BM3ORUNO22

BM3ORUNO23 BM3ORUNO24 BM24ECLO01 BM24RUN001 BM24RUNOO2 BM24RUNO03

BM24RUN004 BM24RUNO05 BM24RUNO06 BM24RUN007 BM24RUN008 BM24RUNO09

BM24RUN010 BM24RUNO11 BM25ECL001 BM25RUN001 BM25RUN002 BM25RUNO03

BM25RUNO04 BM25RUNO05 BM25RUNO06 BM25RUNO07 BM25RUNO08 BM25RUNO09

BM25RUNO10 BM25RUN011 BM25RUN012 BM25RUNO13 BM25RUN014 BM25RUN015

BM25RUN016 BM25RUNO17 BM25RUNO18 BM25RUNO19 BM25RUNO20 BM25RUNO21

BM25RUNO22 BM25RUNO23 BM25RUNO24 BM25RUNO25 BM25RUNO26 BM25RUNO27

BM25RUNO28 BM25RUNO29 BM25RUN030 BM25RUN031 BM25RUN032 BM25RUN033

BM25RUN034 BM25RUNO35 BM25RUNO36 BM25RUN037 BM25RUN038 BM25RUN039

BM25RUNO40 BM25RUN041 BM25RUN042 BM25RUNO43 BM25RUNO44
\end{abstract}




\title{
A.6 PCA2 Benchmark Staging Order
}

The following is a selection of text from the script which controls the execution order of each benchmark iteration to be run on this chassis. Benchmarks in the witnessed configuration were staged in the same order as those in the proposal.

\begin{abstract}
alljobs $=$ BM02ECL001 BM01ECL001 BM31ECL001 BM31RUN002 BM01RUN001 BM01RUN004 BM01RUNO03 BM01RUN005 BM01RUN002 BM31RUN001 BM02RUN003 BMO2RUNO05 BMO2RUNO02 BMO2RUNO04 BMO2RUNO01 BM02RUNOO6 BM23ECLO01 BM23RUNO04 BM23RUN001 BM23RUN003 BM23RUN002 BM23RUNO05 BM27ECL001 BM27RUN027 BM27RUNO09 BM27RUN033 BM27RUN007 BM27RUN002 BM27RUN003 BM27RUNO04 BM27RUNO05 BM27RUN006 BM27RUN021 BM27RUN032 BM27RUN022 BM27RUN030 BM27RUN011 BM27RUN012 BM27RUN013 BM27RUN014 BM27RUN015 BM27RUN016 BM27RUN018 BM27RUN019 BM27RUN020 BM27RUN023 BM27RUN024 BM27RUNO25 BM27RUN026 BM27RUN028 BM27RUN029 BM27RUN034 BM27RUN035 BM27RUN017 BM27RUN031 BM27RUN001 BM27RUN010 BM27RUN008
\end{abstract}


Appendix B

Supporting Data: CRAY T3E 


\section{B.1 Proposed CRAY T3D Configuration}

The following is selected output from a log file provided with the CRAY T3D benchmark data.

Basic configuration was Y-MP $8 \mathrm{E}$ with 4 processors and $64 \mathrm{Mw}$ with 12 channels of $\mathrm{DD}-60$ disk drives.

The Y-MP is attached to a 256 node Cray T3D system with two high-speed connections.

$\cdots$

This is a 4-CPU, $64 \mathrm{MW}$ system

HARDWARE: SERIAL $=$ SN 1049 MFTYPE $=$ CRAY $-Y M P$

MFSUBTYPE $=$ YMPOXX NCPU $=4 \quad \mathrm{CPCYCLE}=6.0000 \mathrm{~ns}$

MEM $=67106560 \quad$ NBANKS $=128 \quad$ CHIPSZ $=262144$

$\mathrm{AVL}=\mathrm{YES} \quad \mathrm{BDM}=\mathrm{YES} \quad \mathrm{EMA}=\mathrm{YES} \quad \mathrm{HPM}=\mathrm{YES} \quad \mathrm{BMM}=\mathrm{NO}$

$S S D=134217728 \quad$ NVHISP $=2$ IOS= MODEL_E

SOFTWARE: RELEASE $=8.00$ POSIX VERSION $=199009$ SECURE SYS $=$ OFF

SYSMEM $=10020864$ WRDS USRMEM $=57085696$ WRDS

OS_HZ $=60 \quad$ CLK_TCK $=166666667$

JOB_CONTROL $=$ YES SAVED_IDS $=$ YES SCTRACE $=$ ON

UID_MAX $=60000 \quad$ PID_MAX $=100000$

ARG_MAX $=49999$ CHILD_MAX $=500 \quad$ OPEN_MAX $=1024$

NMOUNT $=200 \quad$ NUSERS $=200 \quad$ NPTY $=255$

$\mathrm{NDISK}=256 \quad \mathrm{SDS}=0 \quad \mathrm{NBUF}=5000$

PRIV_SU $=$ ON $\quad$ PRIV_TFM $=$ OFF

$\cdots$

You are running at the following UNICOS level

typhoon 8.0.3av roo.13 CRAY Y-MP

Here are the asynchronous product versions running on this system at this time

as version $C C$ version CRAY-T3D

4.0.3.4

CC version 1.0.3.1

$\mathrm{cdbx}$ version 8.1.0.6

cft77 version

debug version 8.1.0.6

fmp version 6.0.4.0

fpp version 6.0

pascal version 4.2 .3 .0 
segldr version $8.0 \mathrm{~h}$

Cray Standard C Version 4.0.3.1 (097512) May 41995 23:23:41

Cray F90 Version 1.0 (1.68) 05/04/95 23:14:49

cf90: Cray CF90 Version 0.1.1.0 (037612) Thu May 4, 1995 23:14:50

Cray F90 Version 1.0 (1.73) 05/04/95 23:15:10

cf90: Cray CF90 Version 0.1.2.0 (118966) Thu May 4, 1995 23:15:12

PPLDR version 10.w - 01/02/95

typhoon [ jpb ]9164: uname -a

sn1049 typhoon 8.0.3av roo.13 CRAY Y-MP

sn1049 - Thu May 4 18:49:07 CDT 1995 


\section{B.2 Installed CRAY T3E Configuration}

The following is the output from the sysconf command on the CRAY T3E. Note that although the system has 256 nodes only 80 of those nodes are contractor provided and thus eligible for benchmarking.

Hardware:

\begin{tabular}{|c|c|}
\hline System serial number & SN6323 \\
\hline Mainframe type $\ldots \ldots \ldots \ldots$ & CRAY-T3E \\
\hline Mainframe subtype ........ & T3EXXXX \\
\hline Number of available CPUs & 1 \\
\hline Cycle time in nanosecs (LPE OxOf5) & 3.3330 \\
\hline Clock ticks per second (LPE OxOf5) & \\
\hline
\end{tabular}

\section{Software:}

Operating system $\ldots \ldots \ldots \ldots \ldots$ UNICOS/MK

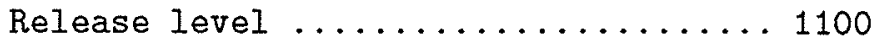

Kernel generation date and time ..... 02/03/97 10:08:00

Max PEs avail to application ........ 245

Level of Posix conformance ......... 199009

SECURE_SYS option ............. NORMAL

Operating system ticks per second .... 100

Posix Job Control implemented ....... YES

Max number of open files (current) ...664

Max number of open files (Iimit) ....664

Max value for User-ID .............6 60000

Max value for Process-ID ........... 100000

Max length of args for exec() ....... 49999

Max number of processes per user .... 95

Max number of multi-group groups ....664

Max number of ptys ............ 128

Number of mount points configured .... 150

Number of users configured ......... 200

Number of I/O cache blocks ........77000

SCTRACE enabled ............... NO

exec() saves IDs ............. YES

Running under a simulator .......... NO

Max size of timezone name ......... 128

Root privilege policy ........... ON

Posix privilege policy ........... OFF

TFMgmt priv policy under MLS ........ OFF

Enforce system high/low MAC ........ OFF

Secure mkdir(2) option ........... OFF

Size of kernel \& tables (LPE 0x0f5) . 10485760

User memory available (LPE OxOf5) ... 123731968 
The output of the uname command follows, with information on $\mathrm{C}$ and Fortran90 compiler version information.

sn6323 jim 1.3.160 unicosmk CRAY T3E

Cray Standard C Version 5.0.3.0 (d29p35m275a35) Feb 28 1997 10:27:23

Cray CF90 Version 2.0.3.1 02/28/97 10:27:20 



\section{REPORT DOCUMENTATION PAGE}

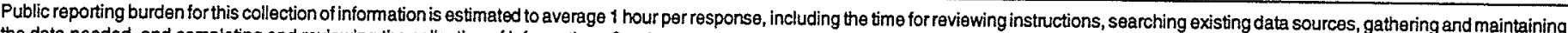

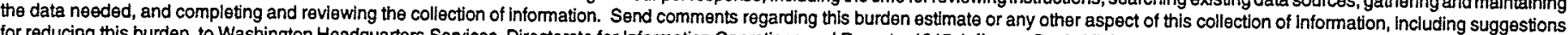

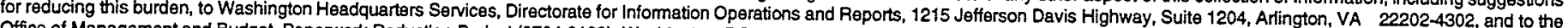
Office of Management and Budget, Paperwork Reduction Project (0704-0188), Washington, DC 20503.

\begin{tabular}{|l|l|l|l}
\hline 1. AGENCY USE ONLY (Leave blank) & $\begin{array}{l}\text { 2. REPORT DATE } \\
\text { May } 1997\end{array}$ & $\begin{array}{l}\text { 3. REPORT TYPE AND DATES COVERED } \\
\text { Preliminary report }\end{array}$
\end{tabular}

4. TITLE AND SUBTITLE

U.S. Army Engineer Waterways Experiment Station Major Shared Resource

5. FUNDING NUMBERS

Center Benchmark Results and Analysis; Performance Level 1

6. AUTHOR(S)

John E. West, Alex R. Carrillo

7. PERFORMING ORGANIZATION NAME(S) AND ADDRESS(ES)

U.S. Army Engineer Waterways Experiment Station

3909 Halls Ferry Road

Vicksburg, MS 39180-6199

8. PERFORMING ORGANIZATION REPORT NUMBER

Technical Report ITL-97-3

9. SPONSORING/MONITORING AGENCY NAME(S) AND ADDRESS(ES)

U.S. Army Corps of Engineers

10. SPONSORING/MONITORING

Washington, DC 20314-1000

AGENCY REPORT NUMBER

11. SUPPLEMENTARY NOTES

Available from National Technical Information Service, 5285 Port Royal Road, Springfield, VA 22161.

12a. DISTRIBUTION/AVAILABILITY STATEMENT

Approved for public release; distribution is unlimited.

12b. DISTRIBUTION CODE

13. ABSTRACT (Maximum 200 words)

Upon installation of the Performance Level 1 target High-Performance Computing configuration in the Department of Defense U.S. Army Engineer Waterways Experiment Station Major Shared Resource Center, the Government's integration contract requires that the contractor demonstrate that the performance levels achieved by the installed configuraton match those cited in the offeror's final pre-award proposal. This report details the analysis of the results of this demonstration, and enumerates several areas of concern that must be addressed before the witnessed benchmark is recommended as successfully complete.

14. SUBJECT TERMS

High-Performance Computing Systems Analysis

Operations research

Computer Benchmarks

15. NUMBER OF PAGES

41

16. PRICE CODE

17. SECURITY CLASSIFICATION 18. SECURITY CLASSIFICATION OF REPORT OF THIS PAGE

19. SECURITY CLASSIFICATION

20. LIMITATION OF ABSTRACT

UNCLASSIFIED

UNCLASSIFIED

NSN 7540-01-280-5500

Standard Form 298 (Rev. 2-89)

Prescribed by ANSI Std. Z39-18

298-102 
